\title{
Intrinsic Endobronchial Obstructions in Children from Turkey: Evaluation of 2,555 Flexible Bronchoscopic Procedures
}

\author{
Arif Kut $^{\mathrm{a}} \quad$ Erkan Cakir $^{\mathrm{b}}$ Yasemin Gokdemir ${ }^{\mathrm{c}} \quad$ Levent Midyat $^{\mathrm{a}}$ Refika Ersu $^{\mathrm{c}}$ \\ Ela Erdem ${ }^{c}$ Bulent Karadag ${ }^{c}$ Fazilet Karakoc ${ }^{c}$ \\ a Department of Pediatric Pulmonology, Sureyyapasa Chest Diseases and Thoracic Surgery Training and \\ Investigation Hospital, b Department of Pediatric Pulmonology, Bezmialem Vakif University Faculty of Medicine, \\ and ${ }^{C}$ Department of Pediatric Pulmonology, Marmara University Faculty of Medicine, Istanbul, Turkey
}

\section{Key Words}

Endobronchial lesions • Bronchial obstructions • Child •

Flexible bronchoscopy $\cdot$ Pediatrics

\begin{abstract}
Background: Endobronchial obstructions are rarely seen in children and are often misdiagnosed resulting in delay of definitive treatment. A variety of diseases can cause endobronchial obstructions in childhood, but data is limited as to the frequency, distribution and clinical characteristics of endobronchial obstructions diagnosed with flexible bronchoscopy (FB). Objective: To document endobronchial obstructions detected by FB. Methods: FB results from three pediatric pulmonology centers in Istanbul were evaluated. Results: A total of 2,555 children underwent an FB procedure during the study period. Endobronchial obstructions were detected in $10 \%(n=256)$ of the patients. Among FB in patients who had endobronchial obstructions, the four most common indications for bronchoscopy were persistent infiltrations $(30 \%, \mathrm{n}=72)$, persistent wheezing $(28 \%, \mathrm{n}=70)$, chronic cough $(26 \%, n=66)$ and atelectasis $(23 \%, n=59)$. The most common endobronchial obstructions detected in the patients were aspirated foreign bodies $(35.9 \%, \mathrm{n}=92)$, endobronchial tuberculosis $(31.6 \%, n=81)$, mucous plugs occlud-
\end{abstract}

ing airway $(16.7 \%, n=43)$ and granulation scars $(6 \%, n=16)$. Other pathologies included hydatid cysts $(n=5)$, hemangiomas $(n=5)$, tumors $(n=5)$, submucosal nodules $(n=5)$ and polyps $(n=4)$. Endobronchial obstructions were most commonly located in the right bronchus $(51 \%, \mathrm{n}=130)$ followed by the left bronchus ( $33 \%, n=85)$, bilaterally $(8 \%, n=21)$ and trachea $(8 \%, n=20)$. Conclusions: Endobronchial obstructions can be caused by a number of different diseases which require various medical or surgical treatments. In the presence of clinical or radiological findings suggesting an endobronchial obstruction, FB should be performed promptly.

Copyright $\odot 2012$ S. Karger AG, Basel

\section{Introduction}

Endobronchial obstructions are infrequently seen in children and they are often misdiagnosed resulting in delay of definitive treatment. A variety of diseases can cause endobronchial obstructions in childhood. Foreign bodies and impacted mucus are among the most commonly reported [1-4], followed by tuberculosis (TB)-related lesions and neoplasms [5-7]. Other less commonly reported causes are polyps, endometriosis, atypical mycobacterial infections and hydatid cyst membranes [8-11].

\section{KARGER}

Fax +4161306 1234

E-Mail karger@karger.ch

www.karger.com (c) 2012 S. Karger AG, Basel

0025-7931/13/0851-0043\$38.00/0

Accessible online at:

www.karger.com/res
Erkan Cakir

Department of Pediatric Pulmonology

Bezmialem Vakif University Faculty of Medicine

TR-34093 Fatih, Istanbul (Turkey)

E-Mail erkancakir1@yahoo.com 
Endobronchial obstructions should be considered in the differential diagnosis of children with respiratory symptoms who do not respond to standard medical therapy. Diagnosis and treatment of endobronchial obstructions can be challenging depending on the etiology. These obstructions can be diagnosed best by flexible bronchoscopy (FB) in order to directly view the pathology and, when indicated, perform a biopsy $[12,13]$.

Case reports or case series concerning only one of the causes of endobronchial obstructions in childhood are reported $[2,6-8,11]$. Some studies have revealed the presence of endobronchial diseases in certain conditions such as persistent atelectasis [3]; however, only a few studies have reported a spectrum of endobronchial obstructions in a wider group of children who underwent an $\mathrm{FB}$ procedure $[4,14]$. In this study, we aimed to evaluate the underlying etiologies of endobronchial lesions in childhood as well as the treatment and follow-up of these lesions.

\section{Materials and Methods}

For this study we reviewed medical records of pediatric cases with respiratory disease patients who had undergone FB between 1997 and 2011 in three pediatric pulmonology centers in Istanbul, Turkey: Marmara University Faculty of Medicine, Sureyyapasa Chest Diseases and Thoracic Surgery Training and Investigation Hospital, and Bezmialem Vakif University Faculty of Medicine. Patients' medical records provided information as to demographic characteristics, symptoms at presentation, FB findings and available follow-up data including treatment modalities.

\section{Flexible Bronchoscopy}

All FBs were performed in the procedure room. Patients received midazolam and pethidine hydrochloride (meperidine) as premedication and lidocaine was used as a topical anesthetic. During the procedure, all patients were given oxygen and monitored with a pulse oximeter. An experienced assistant and nurse were present during the procedures to evaluate the patient status and to administer medications. Transnasal FB was performed using the Olympus, BF 3C160. Permission was received from the Marmara Medical Faculty Ethics Committee. Informed consent for FB procedures and use of the findings for research was obtained from the parents.

\section{Statistics}

Statistical analysis was performed using SPSS for Windows 18.0. We describe numerical parameters with mean and median values, and investigate the distributions of the categorical measurements by frequency and percentages.

\section{Results}

During the study period a total of 2,555 children with chronic respiratory symptoms underwent $\mathrm{FB}$ procedures. Endobronchial obstructions were detected in $10 \%(\mathrm{n}=$ 256) of these patients. The median age was 36 months (interquartile range 12-108) and the median duration of respiratory symptoms at presentation was 4 months (interquartile range $1.5-8)$. Fifty-nine percent $(n=150)$ of the subjects were male.

Persistent infiltrations ( $30 \%, \mathrm{n}=72$ ), persistent wheezing $(28 \%, \mathrm{n}=70)$, chronic cough $(26 \%, \mathrm{n}=66)$ and atelectasis $(23 \%, \mathrm{n}=59)$ were the most common indications for FB in patients who had endobronchial obstructions, followed by suspicion of foreign body aspiration (FBA; $16 \%, \mathrm{n}=43)$, stridor $(11.3 \%, \mathrm{n}=29)$ and difficult asthma $(5 \%, \mathrm{n}=13)$. More than one indication was found in 96 patients. Distribution of the endobronchial obstructions in the study group is presented in table 1.

Retained foreign bodies were the most common cause of endobronchial obstructions $(n=92)$. Either a history of FBA was absent (54\%) or a low index of suspicion was present (46\%). Aspirated foreign bodies were organic in nature in $82 \%$ of the patients and the mean duration of symptoms was $5.9 \pm 3.2$ months.

FB revealed endobronchial TB in 81 patients. Of these, $65 \%$ were already on anti-TB treatment and FB was performed because of persistent infiltration in spite of appropriate treatment. The most common endobronchial TB lesions were white caseous lesions (38\%), followed by polypoid mass (30\%) and granulation tissue (9\%). Lesions were of mixed types in $23 \%$ of the patients.

In 43 patients with a history of unresolved atelectasis, FB revealed total occlusion of an airway with a mucous plug. The underlying diseases of the mucoid impaction were lower respiratory infection in 11 cases, asthma in 9, bronchiectasis and cystic fibrosis in 8 cases each, primary ciliary dyskinesia in 5 and allergic bronchopulmonary aspergillosis in 2 cases. In 34 patients, bronchial lavages with saline removed the airway plugs. In 9 patients who had thicker mucous plugs, rigid bronchoscopy was required in order to clean the plugs and resolve the atelectasis.

Hydatid cyst membrane was diagnosed in 5 patients. These patients had atypical radiological and clinical findings for hydatid disease and they presented with hemoptysis and persistent infiltration/atelectasis on chest X-ray. FB revealed white gelatinous endobronchial lesions in these patients and serology confirmed the diagnosis. In 2 patients, pathological examination showed the typical 
Table 1. Causes of endobronchial obstructions in 256 pediatric patients

\begin{tabular}{|c|c|c|c|c|c|}
\hline Aspirated foreign body & $92(35.9)$ & $44.4 \pm 20.4$ & $24(9-168)$ & $5.9 \pm 3.2$ & $2(1-84)$ \\
\hline Endobronchial tuberculosis & $81(31.6)$ & $76.9 \pm 56.8$ & $81(7-192)$ & $4.7 \pm 3.7$ & $4(2-12)$ \\
\hline Hydatid cyst & $5(1.9)$ & $120.0 \pm 36.0$ & $108(72-156)$ & $10.2 \pm 7.2$ & $8(1-24)$ \\
\hline Hemangioma & $5(1.9)$ & $4.7 \pm 0.7$ & $5(3.5-5)$ & $4.6 \pm 0.4$ & $5(3-5)$ \\
\hline Endobronchial submucosal nodule & $5(1.9)$ & $88.2 \pm 47.4$ & $108(9-132)$ & $41.3 \pm 42.7$ & $40.5(1-84)$ \\
\hline Tumors & $5(1.9)$ & $115.4 \pm 71.6$ & $93(84-164)$ & $6.2 \pm 3.6$ & $3(2-18)$ \\
\hline Squamous papilloma & 2 & 92.5 & & 3.0 & \\
\hline Inflammatory myofibroblastic tumor & 1 & 144.0 & & 18.0 & \\
\hline
\end{tabular}

three-layered structure of hydatid cyst. Four patients were cured successfully with medical treatment while 1 patient required surgical resection of the cyst.

Endobronchial submucosal nodules elevated from the mucosa and resembling cobblestones were present in 5 patients. Biopsy confirmed Hodgkin's lymphoma $(n=2)$, sarcoidosis $(\mathrm{n}=1)$ and tracheobroncho-osteochondropathy (TBO; $\mathrm{n}=1)$ in 4 of these patients. No underlying disease was identified in the fifth, and the submucosal nodules disappeared during follow-up.

Bronchial polyps were found in 4 patients. Three patients had one polyp and 1 patient had two polypoid lesions. One patient had a history of prolonged intubation and the polyp was smaller at the follow-up FB. Pathological evaluation of the other polyps showed inflammatory cells which had completely disappeared by follow-up.

Five tumoral lesions, two malignant (carcinoid tumor and mucoepidermoid carcinoma) and three benign (squamous papilloma and inflammatory myofibroblastic tumors), were diagnosed with biopsy. Surgical resection was performed for the malignant tumors while the benign lesions were followed without any intervention.

Endobronchial obstructions were most commonly located in the right bronchus $(51 \%, \mathrm{n}=130)$ followed by the left bronchus (33\%, $\mathrm{n}=85)$, bilaterally $(8 \%, \mathrm{n}=21)$ and trachea $(8 \%, n=20)$. Different bronchoscopic views of the patients are presented in figure 1 and 2 .

All of the patients identified as having foreign bodies $(\mathrm{n}=92)$ were referred to rigid bronchoscopy. Nine of the mucous plugs were removed via rigid bronchoscopy. Ad- ditionally, rigid bronchoscopy was performed in order to obtain biopsy in cases with tumors $(\mathrm{n}=5)$, polyps $(\mathrm{n}=4)$ and submucosal nodules $(n=5)$. During FB, only $6 \%$ of the patients had minor complications such as transient hypoxia, stridor and tachycardia, and there was no major complication.

\section{Discussion}

In this large series of FB in children, $10 \%$ of the children had endobronchial obstructions. Aspirated foreign bodies, endobronchial TB, mucous plugs and granulation scars were the most common causes, followed by relatively rare conditions such as membrane of hydatid cyst, hemangioma, tumor, submucosal nodule and polyps.

Similar to our study, Wood [4] reported that foreign bodies, mucous plugs and granulation tissues were the most frequent endobronchial obstructions in his $828 \mathrm{FB}$ series. Among 420 FBs, Eber and Zach [14] reported 36 cases of obstructing granulation tissue, 5 subglottic hemangiomas and 5 endobronchial foreign bodies as endobronchial obstructions. Vijayasekaran et al. [3] showed that the underlying endobronchial obstructions in 56 children with persistent atelectasis were mucous plugs $(\mathrm{n}=16)$, granulation tissue due to TB $(\mathrm{n}=2)$ and foreign bodies $(n=2)$.

In the present study, the most frequent causes of endobronchial obstructions were undiagnosed and retained foreign bodies. Clinical, radiological and bronchoscopic 

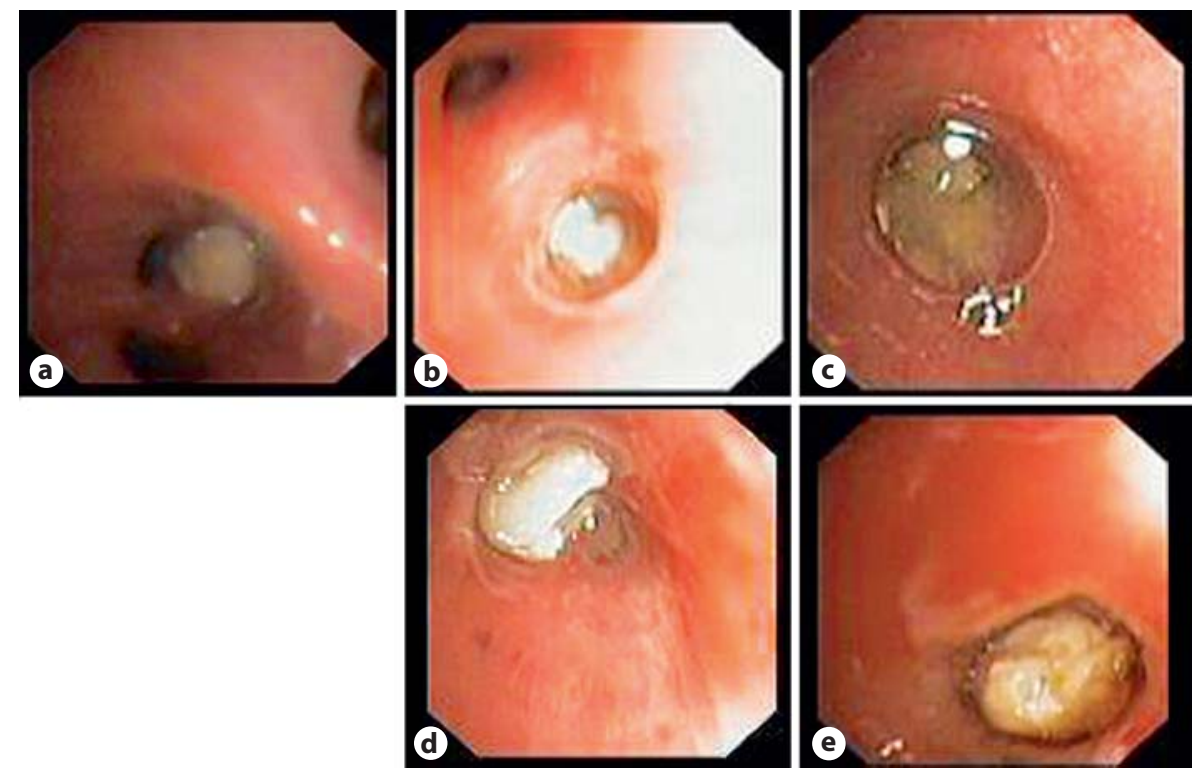

Fig. 1. Different endobronchial obstructions which resemble each other in our patient series: aspirated foreign body (a), endobronchial caseous TB in right lower lobe (b), mucous plug (c), membrane of hydatid cyst (d), and eosinophilic plug in left lingula (e).
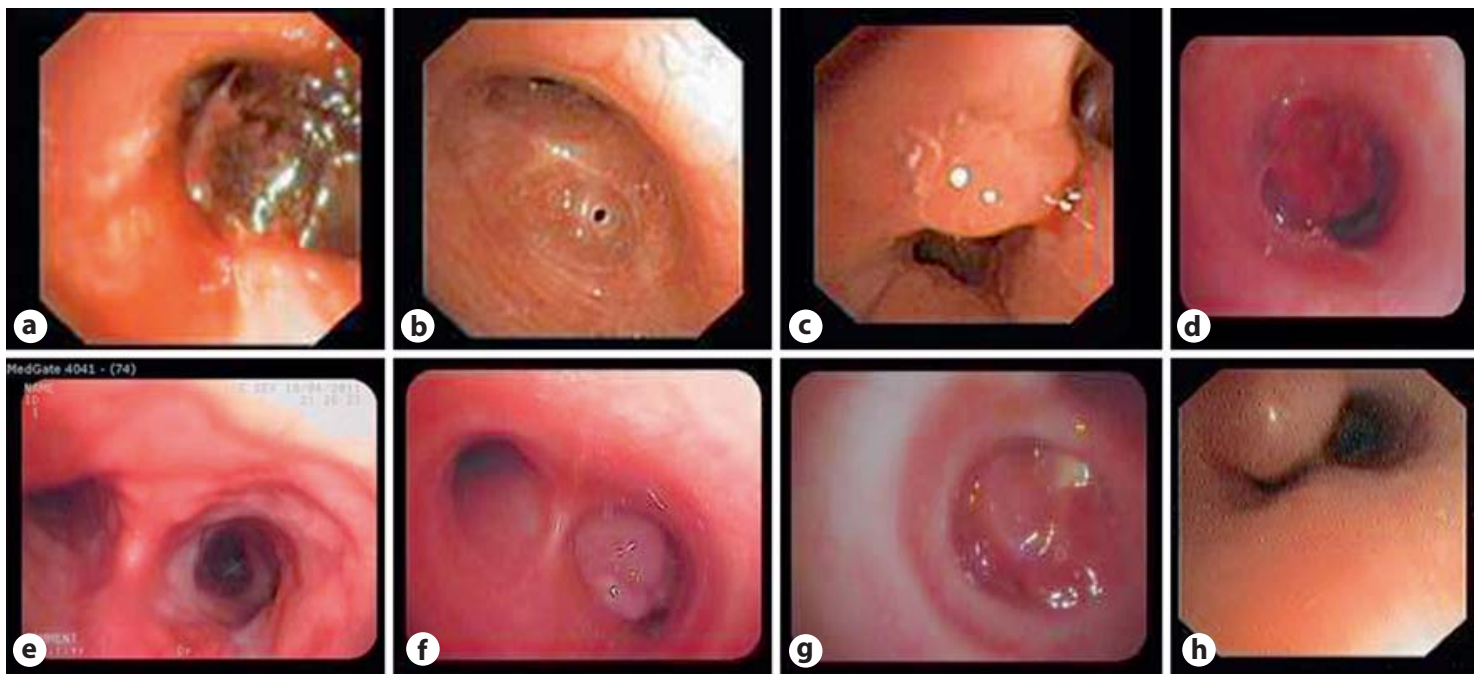

Fig. 2. The pictures of different endobronchial pathologies in our patient series: coagulated mucous plug (a), cicatricial stenosis as a sequela of infection (b), endobronchial TB (polypoid type) in right upper lobe (c), carcinoid tumor (d), submucosal nodule (e), myofibroblastic tumor in right upper lobe (f), aspirated foreign body - a hazelnut $(\mathbf{g})$, and polyp in trachea $(\mathbf{h})$.

findings of the patients with FBA are related to the nature of the foreign body and the time elapsed from aspiration to diagnosis. Rigid bronchoscopy is the preferred procedure for the removal of the aspirated material $[1,15]$; however, in highly suspicious cases with patients who have no history of aspiration, FB provides a safe and simple way to definitively exclude the presence of foreign bodies. History of aspiration was not present in about half of the patients $[1,2]$. In our patients, history of FBA was absent $(54 \%)$ or had a low index of suspicion (46\%). Most of the 
aspirated material was organic in nature and commonly detected in the right main and intermediate bronchi.

Endobronchial TB was the second most common cause of endobronchial obstructions in our study. The reported incidence of endobronchial TB ranged from 41 to $63 \%$ in children; however, the incidence of endobronchial TB is unknown since bronchoscopy is not routinely performed in all patients with TB. Endobronchial TB presents most commonly as caseous lesions, granulation tissue or polypoid mass lesions $[5,6]$. In this study, endobronchial TB was detected in 81 patients and the distribution of the lesions was consistent with the literature $[5,6]$. Of these patients, $65 \%$ were already on anti-TB treatment, but FB was performed because they had persistent clinical and radiological findings despite appropriate treatment. All the patients with endobronchial lesions improved with the addition of steroid therapy except 2 in whom laser ablation was applied.

Mucous plugs may obstruct the airways and lead to atelectasis, causing recurrent respiratory infections or chronic respiratory symptoms. For these patients, detection and removal of mucus plugs via FB has both diagnostic and therapeutic importance $[3,16]$. In our study, all the patients with the mucous plugs had atelectasis. Lavage and aspiration were successfully used in treating the atelectasis in these patients; the few patients with thicker mucus required rigid bronchoscopy.

Hydatid disease is a major health problem in many parts of the world, yet there are few reports about the endobronchial presentation of hydatid cysts in adults and children $[11,17,18]$. Usually, intact lung cysts are discovered incidentally on chest radiographs, thus making FB unnecessary for diagnosis in most cases; however, some patients may present with atypical clinical, serological and radiological findings. The presence of whitish-yellow gelatinous membrane is the typical bronchoscopic finding $[11,17]$. In this study, FB showed that 5 patients had hydatid cysts. FB revealed typical cyst membranes and in 2 patients diagnosis was confirmed by histology.

Bronchial tumors are rare entities during childhood and show a different pathological spectrum from adults. Bronchial carcinoids, invasive fibrous tumors and mucoepidermoid tumors are the most commonly reported tumors in children, followed by endobronchial hamartoma, leiomyoma and schwannoma [7, 19-21]. In our study, FB revealed tumors in 5 patients and biopsy confirmed the diagnosis of carcinoid tumor, mucoepidermoid carcinoma, papilloma and an inflammatory myofibroblastic tumor. Since patients with tumors may present with persistent infiltration and atelectasis, early diagnosis with FB is important in order to prevent morbidity and mortality.

Bronchial polyps are rarely seen in childhood and may occur secondary to long-term intubation or may be inflammatory $[8,22]$. One of our patients had a history of prolonged intubation, and in 3 patients polyps were inflammatory in nature and had disappeared by the time of follow-up.

In the literature, lymphoma, amyloidosis, sarcoidosis, $\mathrm{TB}$ and $\mathrm{TBO}$ are the reported causes of endobronchial nodules [23-26]. In our study, endobronchial nodules were secondary to lymphoma, sarcoidosis and TBO.

Different types of endobronchial lesions may resemble each other in appearance, making a definitive diagnosis difficult. In such patients, endobronchial biopsy and sometimes rigid bronchoscopy are needed to better define the type of lesion [27] (fig. 1, 2).

In conclusion, endobronchial obstructions can be caused by a number of different diseases or conditions which require completely different medical or surgical treatments. FB should be performed promptly in the presence of clinical or radiological findings pointing to an endobronchial obstruction. Early diagnosis of the lesion may prevent morbidity, mortality and unnecessary treatment.

\section{References}

1 Zhijun C, Fugao Z, Niankai Z, Jingjing C: Therapeutic experience from 1,428 patients with pediatric tracheobronchial foreign body. J Pediatr Surg 2008;43:718-721.

-2 Karakoc F, Cakir E, Ersu R, Uyan ZS, Colak B, Karadag B, Kiyan G, Dagli T, Dagli E: Late diagnosis of foreign body aspiration in children with chronic respiratory symptoms. Int J Pediatr Otorhinolaryngol 2007;71:241246.

Endobronchial Obstructions in Childhood
3 Vijayasekaran D, Gowrishankar NC, Nedunchelian K, Suresh S: Fiberoptic bronchoscopy in unresolved atelectasis in infants. Indian Pediatr 2010;47:611-613.

4 Wood RE: The diagnostic effectiveness of the flexible bronchoscope in children. Pediatr Pulmonol 1985;1:188-192.

5 Chan S, Abadco DL, Steiner P: Role of flexible fiberoptic bronchoscopy in the diagnosis of childhood endobronchial tuberculosis. Pediatr Infect Dis J 1994;13:506-509.
Cakir E, Uyan ZS, Oktem S, Karakoc F, Ersu R, Karadag B, Dagli E: Flexible bronchoscopy for diagnosis and follow up of childhood endobronchial tuberculosis. Pediatr Infect Dis J 2008;27:783-787.

7 Al-Qahtani AR, Di Lorenzo M, Yazbeck S: Endobronchial tumors in children: institutional experience and literature review. J Pediatr Surg 2003;38:733-736.

Childhood

Respiration 2013;85:43-48 
8 McShane D, Nicholson AG, Goldstraw P, Ladas G, Travis WD, Ramanan R, BalfourLynn IM, Rosenthal M, Bush A: Inflammatory endobronchial polyps in childhood: clinical spectrum and possible link to mechanical ventilation. Pediatr Pulmonol 2002; 34:79-84.

$\checkmark 9$ Martire B, Loizzi M, Cimmino A, Peruzzi S, De Mattia D, Giordano P: Catamenial hemoptysis from endobronchial endometriosis in a child with type 1 von Willebrand disease. Pediatr Pulmonol 2007;42:386-388.

$>10$ Del Rio Camacho G, Soriano Guillen L, Flandes Aldeyturriaga J, Hemandez Garcia B, Bernacer Boria M: Endobronchial atypical mycobacteria in an immunocompetent child. Pediatr Pulmonol 2010;45:511-513.

- 11 Cakir E, Ozaydin SE, Tasci E, Baran R: Unusual presentation of hydatid cyst: diagnosis with bronchoscopy. J Infect Dev Ctries 2010; 4:352-354.

12 Mu D, Nan D, Li W, Fu W, Xie Y, Liu T, Jin F: Efficacy and safety of bronchoscopic cryotherapy for granular endobronchial tuberculosis. Respiration 2011;82:268-272.

13 Gudbjartsson T, Gudmundsson G: Middle lobe syndrome: a review of clinicopathological features, diagnosis and treatment. Respiration 2012;84:80-86.
14 Eber E, Zach M: Flexible fiberoptic bronchoscopy in pediatrics - an analysis of 420 examinations. Wien Klin Wochenschr 1995; 107:246-251.

15 Kiyan G, Gocmen B, Tugtepe H, Karakoc F, Dagli E, Dagli T: Foreign body aspiration in children: the value of diagnostic criteria. Int J Pediatr Otorhinolaryngol 2009;73:963967.

16 Nussbaum E: Pediatric flexible bronchoscopy and its application in infantile atelectasis. Clin Pediatr (Phila) 1985;24:379-382.

17 Yilmaz A, Tuncer LY, Damadoglu E, Sulu E, Takir HB, Selvi UB: Pulmonary hydatid disease diagnosed by bronchoscopy: a report of three cases. Respirology 2009;14:141-143.

18 Henry P, Khalfallah A, Lakhal A, Hafsa K, Karoni H: Bronchoscopy in the diagnosis of complicated pulmonary hydatid cyst in children. Rev Mal Respir 1984;1:313-317.

19 Abdulhamid I, Rabah R: Endobronchial chondromatous hamartoma in an infant. Pediatr Pulmonol 2003;35:67-69.

20 Hatano M, Takada H, Ohga S, Ohshima K, Saeki I, Tajiri T, Taguchi T, Suita S, Hara T: Epstein-Barr virus-associated bronchial leiomyoma in a boy with cellular immunodeficiency. Pediatr Pulmonol 2006;41:371373.
21 Tansel T, Toker A, Yilmazbayhan D, Gulluoglu M, Dayioglu E: Primary endobronchial schwannoma. J Pediatr Surg 2010;45:22412243.

22 Popat HP, Sinn J, Cooper P: Endobronchial polyp in a neonate. J Paediatr Child Health 2010;46:354-356.

23 Pinto LM, Udwadia ZF: A 12-year-old girl with Hodgkin's diseases presenting as a nonresolving pneumonia and an endobronchial nodule. Indian J Chest Dis Allied Sci 2009 51:241-243.

24 Kirbas G, Dagli CE, Tanrikulu AC, Yildiz F, Bukte Y, Senyigit A, Kiyan E: Unusual combination of tracheobronchopathia osteochondroplastica and AA amyloidosis. Yonsei Med J 2009;50:721-724.

25 Yamada G, Aketa K, Takahashi H, Satoh M, Abe S: Endobronchial lesions of sarcoidosis. Intern Med 2005;44:909-910.

26 Newton RC, Kemp SV, Yang GZ, Darzi A Sheppard MN, Shah PL: Tracheobronchial amyloidosis and confocal endomicroscopy. Respiration 2011;82:209-211.

27 Seifirad S: A randomized controlled trial of hot versus cold biopsy forceps in the diagnosis of endobronchial lesions: strengths, pitfalls, and ethics points in the study designing. Respiration 2011;82:65. 